\title{
Trihalomethane Levels and Their Seasonal Variation in Drinking Water Produced from Thermal Desalination in Kuwait
}

\author{
H.F. Al-Mudhaf ${ }^{1}$ and A.I. Abu-Shady ${ }^{*}, 2$ \\ ${ }^{1}$ College of Technological Studies, Public Authority for Applied Education and Training (PAAET), Kuwait \\ ${ }^{2}$ Ibn Al-Haitham In-Service Training Center, PAAET, Kuwait
}

\begin{abstract}
Drinking water is obtained in Kuwait by blending desalinated seawater with $5-10 \%$ brackish water. Chemical analysis of trihalomethanes (THMs) was performed on 624 water samples collected from private residences and government buildings from December 2003 to May 2005. The highest value recorded $(91.01 \mu \mathrm{g} / \mathrm{L})$, exceeds the maximum contaminant level (MCL) set by the U.S. EPA. Significant variations in the levels of total THMs (TTHMs) either between various sampling locations or between indoor and outdoor sampling points were found. TTHM levels were mostly higher in the outdoor samples. The maximum recorded value of TTHMs in the indoor drinking water has significantly increased from $50.5 \mu \mathrm{g} / \mathrm{L}$ in 1988 (average $25.6 \pm 9.1 \mu \mathrm{g} / \mathrm{L}$ ) to $90.5 \mu \mathrm{g} / \mathrm{L}$ (average $45.5 \pm 2.6 \mu \mathrm{g} / \mathrm{L}$ ) in this study. Brominated THMs are the dominant species, and bromoform is the most dominant one. TTHMs values are found mostly higher in winter, in contrast to other studies on drinking water of freshwater sources.
\end{abstract}

Keywords: Chlorination by-products, trihalomethanes, seasonal variations, drinking water, desalination, Kuwait.

\section{INTRODUCTION}

Water means life, and it represents the basic requirement for any economic, social, and industrial development. Kuwait is located in an arid area characterized by severe weather conditions: very low rainfall and consequently, an absence of rivers and lakes. Kuwait has very limited underground water resources with variable quality and insufficient quantity for domestic use. Kuwait, like many countries of the Arabian Gulf, obtains potable water through the desalination of seawater. Before being distilled the seawater is chlorinated to inhibit marine fouling inside the distillers. The Arabian Gulf, with a single narrow opening to the Indian Ocean, is considered to be one of the most highly polluted regions in the world. Besides naturally present humic and fulvic acids, pollution with elevated levels of organics in seawater results from the discharge of sewage and industrial wastes, spillage of crude oil, leakages of offshore oil-producing rigs, the uncontrolled discharge of ballast water of tankers, and from petrochemical and refinery plants operating along the Gulf coast. The dual-purpose power and desalination plants along Kuwait coast are multi-stage flash (MSF) distillation plants producing distilled water, which is then blended with $5-10 \%$ brackish water to make it potable, chlorinated, and pumped to the distribution system network, where the consumers possess further storage facilities. For domestic or public premises, these facilities are mainly roof tanks $\left(6-12 \mathrm{~m}^{3}\right)$ constructed from fiberglass or polyethylene, in addition to ground reservoirs $\left(20-100 \mathrm{~m}^{3}\right)$ for large buildings. This situation is mainly found in the Arabian Gulf countries and is rarely encountered in other regions of the world.

*Address correspondence to this author at the Ibn Al-Haitham In-Service Training Center, PAAET, Kuwait; E-mail: aasattar44@yahoo.com and ai.abushady@paaet.edu.kw
Water disinfection generates hundreds of disinfection byproducts (DBPs) through reaction between the disinfectant and organic matters occurring in the water [1]. Chlorine is the most widely used disinfectant and has proven successful for controlling water-borne infectious diseases for more than a century. On the other hand, potentially harmful chlorination DBPs (CDBPs) are formed. However, identification of CDBPs and incidences of potential health hazards have created a major issue on the balancing of the toxicodynamics of the chemical species and risk from pathogenic microbes in the supply of drinking water. Trihalomethanes (THMs) are usually the most prevalent CDBPs (others are haloacetic acids, haloacetonitriles, haloketones and chloropicrin). THMs include chloroform (CFM), bromodichloromethane (BDCM), dibromochloromethane (DBCM), and bromoform (BFM). Total THMs (TTHMs) refers to the sum of these four substances. Exposure to THMs is associated with increased risks of bladder and colon cancer $[2,3]$ as well reproductive effects such as intrauterine growth retardation, low birth weight, preterm birth, congenital malformations, and stillbirth [4-9]. TTHM concentration and the formation of individual THM species in chlorinated water strongly depend on the composition of the raw water, on operational parameters, and on the occurrence of residual chlorine in the distribution system [10].

A great number of studies have been conducted worldwide to evaluate the DBPs in drinking water produced from surface and/or ground water. However, only a few studies have addressed the topic when the source of drinking water is seawater and the treatment process is thermal desalination. Of these few studies, most have been conducted in the Arabian Gulf area, since the Gulf countries rely heavily on desalination of seawater as their primary source of drinking water. The chlorination of fresh water (rivers, lakes, well 
waters) produces CFM as the major compound among THMs [11-13], but this is not the case in water produced by desalination of seawater, as shown by several studies carried out primarily in the Arabian Gulf region. Early in the 1980s, Ali and Riley performed three studies in Kuwait [14-16] on the levels and distribution of THMs in seawater, in various stages of the desalination process, and in the final blended potable water. They reported measured levels of BFM ranging from $10-90 \mu \mathrm{g} / \mathrm{L}$, which comprise $95 \%$ of TTHMs in the vicinity of various power/desalination plants in the Kuwaiti coastal water between March and April 1982 [14]. In the distillate, they found that THM concentrations vary from one plant to another with an average of $2.7-22.8 \mu \mathrm{g} / \mathrm{L}$ but rarely exceed $30 \mu \mathrm{g} / \mathrm{L}$ [15]. In the final potable water [16], they reported a maximum value of $50.5 \mu \mathrm{g} / \mathrm{L}$ for TTHMs, with an average of $25.6 \pm 9.1 \mu \mathrm{g} / \mathrm{L}$; the average concentrations of the brominated species of CFM, DBCM, and BDCM were found to be $13.6 \pm 4.6,8.8 \pm 3.7$, and $3.3 \pm 1.5 \mu \mathrm{g} / \mathrm{L}$, respectively. Water from rooftop storage tanks contained significantly lower THMs than those from underground reservoirs. During the period from April to August 1988, Latif et al. [17] monitored the levels of the four THMs in the distillate produced in Kuwait by one MSF plant that utilized additive antiscalent compounds. They found that the average levels of THM in seawater and distillate were 28.4 and $3.2 \mu \mathrm{g} / \mathrm{L}$, with BFM dominant, and represented $92.6 \%$ and $83.2 \%$, respectively. They reported that the relative concentration of THMs in process streams depended on temperature, $\mathrm{pH}$, total organic carbon (TOC), and residual chlorine, of which the last variable is the most important. Also, Saeed et al. [18] investigated the presence of halogenated volatile liquid hydrocarbons (HVLHs) in the vicinity of inlets and outlets of power/desalination plants in Kuwait. The results showed that THMs contributed the bulk of the total HVLHs, of which BFM constituted more than $87 \%$. They concluded that cooling-water discharges significantly contributed to the formation of the detected HVLHs. In United Arab Emirates (UAE), several studies were carried out on the Abu Dhabi water-distribution system [19], on the coastal intake seawater [20], throughout the plant's influent and effluent, and after several distillation stages inside the plant [21]. The results showed that most of the BFM formed in the final drinking water could be attributed to either BFM that already existed in the intake seawater and was not removed by thermal desalination stages or was newly formed BFM due to the reaction of chlorine added at post-treatment and the trace organic precursors not removed by thermal desalination. Kutty et al. [22] reported the presence of THMs in chlorinated seawater, product distillate, and blended samples from seawater MSF plants on the eastern coast of Saudi Arabia. It was also found that among the three brominated methanes, BFM was the most dominant halomethane.

In a similar study conducted in Greece on drinking water produced from the desalination of Mediterranean seawater [23], the brominated DBPs were found to be more abundant than their chlorinated homologues due to the high concentration of bromide in raw coastal water. Wu et al. [24] conducted a study that implied that thermal distillation may not totally inhibit the formation of halogenated DBPs. They in- vestigated the effect of boiling and heating drinking water on the generation and destruction of DBPs. The experiments were conducted on three samples: DBPs-spiked reagent water, municipal tap water, and synthetic water containing aquatic humic substances. The results showed that chemical transformation occurs at elevated temperatures, where large halogenated THMs and HAAs lead to the formation of smaller chlorinated ones.

A common finding of these previous studies is that brominated THMs are the most dominant byproducts that form upon chlorinating both the bromide-rich seawater source used for desalination and the final potable water produced, in which BFM is the main formed THM species. Formation of these haloforms is found to depend on factors like chlorine dosage, contact time, concentration of $\mathrm{Br}^{-}$ion, temperature, $\mathrm{pH}$, precursors concentration, etc. [25].

The invasion of Kuwait in 1990 and its liberation in 1991 was followed by the spillage of tens of millions of barrels of crude oil in the Arabian Gulf. In addition, the fires of 745 oil wells as well as the military operations throughout the Gulf crises and its consequences after 2002 have heavily increased pollution in the Gulf's seawater. As is evident from the previous literature survey, there are no recent studies that have been performed either to investigate the effect of these crises on the levels of THMs in drinking water in various areas within Kuwait, which are supplied by various desalination plants, or the variation of seasonal conditions on these levels. The objectives of this study were to 1) survey the levels of THMs in indoor and outdoor household drinking water in various areas of Kuwait, which are fed by the product of the five desalination plants; 2) correlate these levels with the coastal source of desalinated water; 3) study the effect of seasonal variations on TTHMs levels; and 4) determine whether values exceed the maximum levels recommended by the US EPA.

\section{MATERIALS AND METHODS}

\section{Reagents and Reference Materials}

Volatile- and organics-free water obtained from the Millipore Ultra Pure Water Purification System (Millipore, Bedford, MA, USA) was used for all required preparations. Certified high-purity organic solvents, chemicals, individual calibration standards and mixes, and quality control as well as reference materials were obtained from Honeywell Burdick \& Jackson, AccuStandard, Supelco, Chemservice, and Agilent companies.

THMs were determined by using Agilent $6890 / 5975 \mathrm{~N}$ Gas Chromatography/ Mass Spectrometry-GC/MS (Agilent, Palo Alto, CA, USA) equipped with Tekmar purge and trap autosampler and preconcentrator system according to US EPA method 524.2 [26]. In this method, THMs and surrogates with low water solubility are extracted (purged) from the sample matrix by bubbling helium gas through the aqueous sample. Purged sample components are trapped in a tube containing suitable sorbent materials. When purging is complete, the sorbent tube is heated and backflushed with helium to desorb the trapped sample components into a capillary GC column interfaced to the MS. The column is temperature 
programmed to facilitate the separation of the method analytes, which are then detected with the MS. Compounds eluting from the GC column are identified by comparing their measured mass spectra and retention times to reference spectra and retention times in a database. Reference spectra and retention times for analytes are obtained by the measurement of calibration standards under the same conditions used for samples. Analytes are quantified using procedural standard calibration. The concentration of each identified component is measured by relating the MS response of the quantification ion produced by that compound to the MS response of the quantification ion produced by a compound used as an internal standard. Surrogate analytes, whose concentrations are known in every sample, are measured with the same internal-standard calibration procedure.

Quality control for the four THMs was performed according to the conditions specified by US EPA method 524.2. This includes analysis of laboratory reagents and field blanks, fortified blanks, and samples as a continuing check of performance. Rinse blanks and six calibrated standard solutions of all monitored analytes were used at ppb concentrations for the different analytes and as specified in the method. On the other hand, in order to extra assure the results obtained for THMs, 16 of the collected water samples were analyzed for THMs by an accredited lab (The University Hygienic Lab (UHL), The University of Iowa, Iowa City, IA) in January and July 2004, in addition to the analysis performed in this study. The results obtained in this study were matched with those of UHL within $\pm 3-5 \%$ difference for various THM species.

\section{Sampling}

Water samples were collected from private residencies (houses and apartments) and government buildings at 99 locations in 69 neighborhoods of the 6 Governorates of the State of Kuwait. One sampling location was selected for repeated sampling within each of the 69 neighborhoods, designated as primary sampling locations. Of the same 69 locations (buildings) in the 69 neighborhoods, an additional 30 locations (in 30 of the 69 neighborhoods) were selected for one-time sampling, designated as secondary sampling locations. Fig. (1) shows the distribution of all sampling locations within various Governorates as well as the desalination plants. Two sampling points, outdoor and indoor, are defined

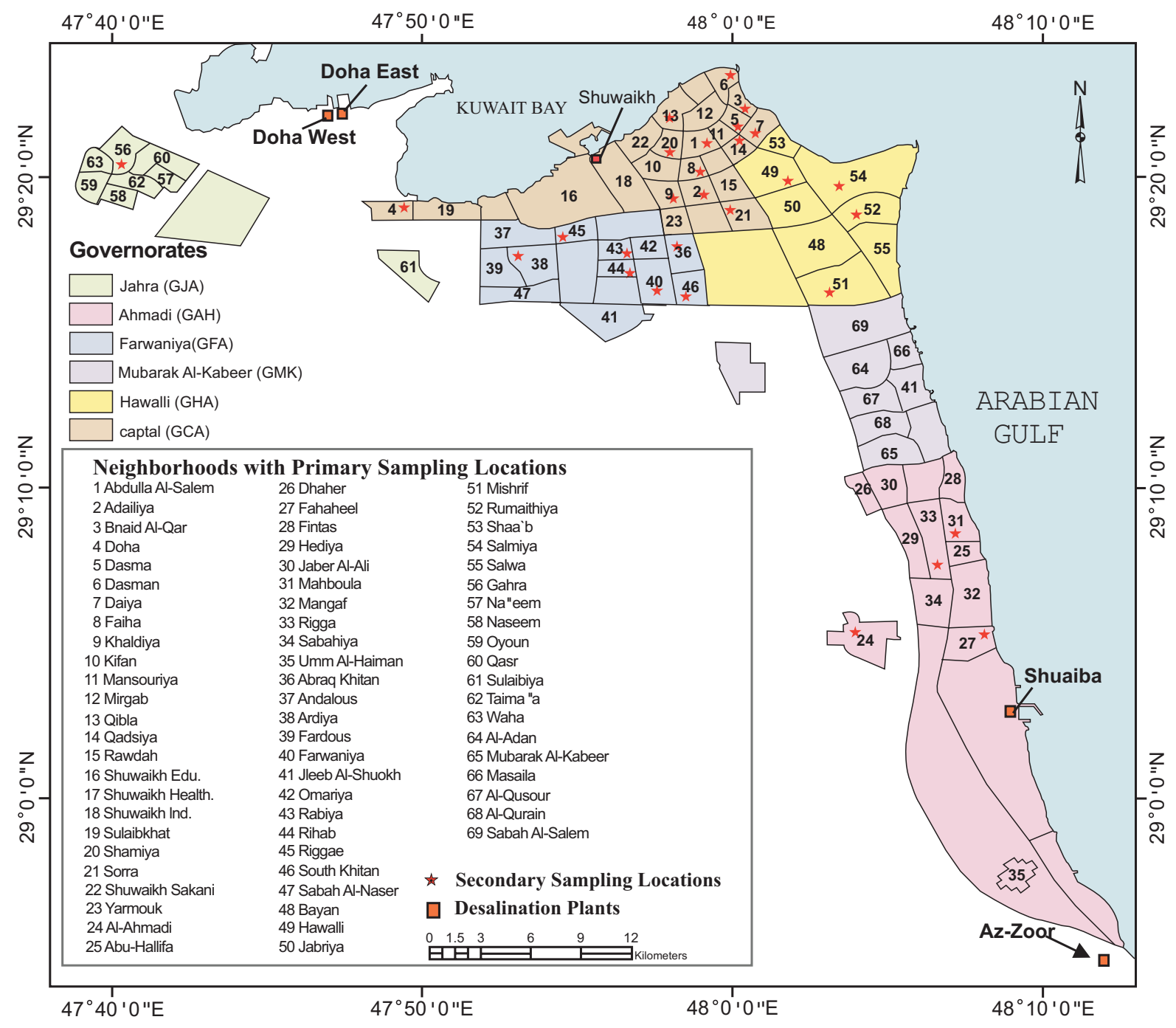

Fig. (1). Location of desalination plants and distribution of sampling Locations within different neighborhoods of the Governorates of Kuwait. 
at each location. Three replicates of each sample were collected and preserved according to US EPA method 524.2. Samples were delivered to the laboratory in dry-ice-cooled boxes, and stored refrigerated (at $4^{\circ} \mathrm{C}$ ) upon arrival until analysis was completed. All water samples were analyzed within the recommended holding times, and any sample exceeding it was discarded.

\section{RESULTS AND DISCUSSION}

Chemical analysis was performed on 624 water samples collected from December 2003 to May 2005. This number includes: 1) 334 samples collected periodically between 7 and 21 times from each of 12 different fixed buildings in 12 different neighborhoods of the State of Kuwait (represented as locations, which represent high-frequency sampling from each individual location), and 2) 290 samples collected from 87 different buildings in other 57 neighborhoods within the six Governorates (represented as Governorates, which rep- resent low-frequency sampling from various locations within each individual Governorate). Table 1 lists the number of collections from each location (or building) and periods of collection. At each time of sampling collection, two samples were collected from two points of each selected building. One from the water connection just outside the building prior to water flow into the building (designated by the letter $-\boldsymbol{O}$-) and the second from an indoor tap after the drinking water had passed through the underground reservoir, plumbing, and rooftop storage tank of the building (designated by the letter $-\boldsymbol{I}$-). Locations and Governorates with their abbreviations are shown in Fig. (1).

According to official information from the Ministry of Electricity and Water (MEW) in Kuwait, the supply of drinking water to various locations in normal operational conditions of the five desalination plants available during the course of this study were mostly from: 1) Az-Zoor plant supplies completely the DUH location. In addition to

Table 1. Numbers of Household Tap Water Samples Collected from Different Locations and the Time Periods of Their Collection

\begin{tabular}{|c|c|c|c|c|}
\hline \multicolumn{5}{|l|}{ A. High Frequency Sampling } \\
\hline CKF & 8 & 16 & $10 / 01 / 2004$ & $28 / 05 / 2005$ \\
\hline CQB & 9 & 18 & $05 / 01 / 2004$ & $28 / 05 / 2005$ \\
\hline $\mathrm{CSH}$ & 8 & 16 & $04 / 02 / 2004$ & $29 / 05 / 2005$ \\
\hline CSL & 8 & 16 & $06 / 12 / 2003$ & $30 / 05 / 2005$ \\
\hline $\mathrm{CSO}$ & 7 & 14 & $24 / 12 / 2003$ & $29 / 05 / 2005$ \\
\hline CSW & 20 & 40 & $12 / 01 / 2004$ & $28 / 05 / 2005$ \\
\hline HSL & 20 & 40 & $08 / 12 / 2003$ & $29 / 05 / 2005$ \\
\hline JOY & 20 & 40 & $23 / 12 / 2003$ & $30 / 05 / 2005$ \\
\hline \multicolumn{5}{|c|}{ B. Low Frequency Sampling from Other Locations within Various Governorates } \\
\hline $\begin{array}{l}i \text { - CAA, CDM, CFH, CQD, JGH, } \\
\text { JNA, JNM, JQA, JSL, JTA, JWA }\end{array}$ & 3 each & 6 each & $24 / 12 / 2003$ & $16 / 12 / 2004$ \\
\hline $\begin{array}{l}i i-\mathrm{CAD}, \mathrm{CBQ}, \mathrm{CDH}, \mathrm{CDS}, \mathrm{CDY} \text {, } \\
\text { CKD, CMN, CMR, CRD, CSI, } \\
\text { CSM, CYA, DAD, DAH, DDH, } \\
\text { DFH, DFN, DHD, DJA, DMH, } \\
\text { DMN, DRG, DSB, FAK, FAN, } \\
\text { FFD, FFR, FJS, FOM, FRB, FRH, } \\
\text { FSK, FSN, HBY, HHW, HJB, } \\
\text { HMS, HRM, HSH, HSW, MAD, } \\
\text { MMK, MMS, MQR, MQU, MSA }\end{array}$ & 2 each & 4 each & $24 / 12 / 2003$ & $26 / 09 / 2004$ \\
\hline
\end{tabular}

Half of this number represents samples collected from the outdoor water connection and the second half from an indoor tap.

Shown in detail in Fig. (1). 
Shuaiba plant, it mainly supplies all locations at the Governorates Ahmadi (GAH) and to a lesser extent the Mubarak Al-Kabeer (GMK); 2) Doha West plant supplies mainly the CSE location, while Doha East supplies mainly all locations of Jahra Governorate (GJA); 3) the Shuwaikh plant supplies mainly the CSW location; and 4) all other individual locations and those within various Governorates are fed by all five of the plants with different proportions or ratios, which may vary daily. Table 2 shows the capacity of various desalination plants.

Table 2. Past, Present and Future Desalination Capacity of MSF plants in Kuwait [28]

\begin{tabular}{|l|c|c|c|}
\hline \multirow{2}{*}{ Desalination Plant } & \multicolumn{3}{|c|}{ Capacity, Million Imperial Gallon Per Day (MIGD) } \\
\cline { 2 - 4 } & Before 2006 & Added After 2006 & Future Addition \\
\hline \hline Shuwaikh & 19.5 & - & - \\
\hline Shuaiba South & 36 & - & - \\
\hline Shuaiba North & - & - & 50 \\
\hline Doha East & 50.4 & - & - \\
\hline Doha West & 110.4 & - & - \\
\hline Az-Zour South & 115.2 & - & - \\
\hline Az-Zour North & - & - & 125 \\
\hline Sabiya & - & 50 & 50 \\
\hline Grand total & $\mathbf{3 3 1 . 5}$ & $\mathbf{5 0}$ & $\mathbf{2 2 5}$ \\
\hline
\end{tabular}

The major objective of drinking water treatment is to provide water that is both microbiologically and chemically safe for human consumption. As chlorine is currently the only disinfectant used for water treatment in Kuwait in order to reduce the risk of pathogenic infection, it forms THMs as the main group of CDBPs, which may pose chemical threat to human health. The United States Environmental Protection Agency (US EPA) has established the maximum contaminant limit (MCL) of $80 \mu \mathrm{g} / \mathrm{L}$ for TTHMs [27]. Fig. (2) illustrates the variation of TTHMs of $\boldsymbol{I}$ and $\boldsymbol{O}$ samples with the date of collection for six of the 12 individual high frequency sampling locations (CSE, CSW, DUH, FRI, HSL, and JOY of collection times 19 to 21). Table 3 depicts the same relation for the other six locations (CKF, CQB, CSH, CSL, CSO and FAR of collection times 7-9) in addition to various locations within each of the 6 Governorates.

Fig. (2) and Table 3 indicate that:

(1) No single general trend is observed for the variation of TTHM levels within various sampling locations, but instead there are several patterns of behavior.

While most of the TTHMs values recorded in the CSE location were significantly higher in comparison to all other locations; DUH showed the lowest values. In other words, the highest values between all of the maximums for $\boldsymbol{I}$ and $\boldsymbol{O}$ samples are found to be 91.0 and $90.5 \mu \mathrm{g} / \mathrm{L}$, respectively in CSE location (above the MCL recommended by US EPA), while DUH showed the lowest $(19.0$ and $16.9 \mu \mathrm{g} / \mathrm{L}$ for $\boldsymbol{I}$ and $\boldsymbol{O}$ samples, respectively) of the maximums, as well as the lowest values between that of all locations (5.2 and $5.0 \mu \mathrm{g} / \mathrm{L}$ for $\boldsymbol{I}$ and $\boldsymbol{O}$ samples, respectively). Also, the DUH, Fig. (2c), illustrates that only 1 of the 19 collections (28 May, 2005) showed significantly higher values of TTHMs $(53.61$ and $42.63 \mu \mathrm{g} / \mathrm{L}$, for $\boldsymbol{I}$ and $\boldsymbol{O}$ samples, respectively) in comparison to those of the 18 remaining collections. This finding may be explained by the fact that the Az-Zoor plant, which services the DUH location, was under partial maintenance at that period and DUH was serviced mainly by other plants, as it is known from the MEW authorities.

All of the other locations show TTHM values between those of CSE and DUH locations.

TTHM levels of most of the samples collected from the secondary locations (shown in Fig. (1) and listed in Table 1) showed no correlation with that of the samples collected from primary locations in approximate dates at the same neighborhood. Only a few samples showed comparable values to those of the primary locations. This means that the level of TTHMs does not depend on the area (neighborhood), but it varies from one building to another in the same area.

Three trends were seen for the levels of TTHMs in $\boldsymbol{I}$ and $\boldsymbol{O}$ samples. While only the CSW location shows significantly higher levels of $\boldsymbol{I}$ samples; five locations (CKF, CSE, CSO, DUH and HSL) and two Governorates (GAH and GMK) show no significant differences between $\boldsymbol{I}$ and $\boldsymbol{O}$ samples. The six locations CQB, CSH, CSL, FAR, FRI, and JOY; in addition to four Governorates GCA, GFA, GHA and GJA exhibit significantly lower values of $\boldsymbol{I}$ samples than that of $\boldsymbol{O}$ samples. The last behavior agrees with the finding of Ali et al. [16], who mentioned that water from rooftop storage tanks (means I samples) contained significantly less halomethanes than that from underground reservoirs (means $\boldsymbol{O}$ samples).

Table 4 and Fig. (3) provide summary statistics of TTHM data for each of the individual 12 locations (high-frequency sampling) as well as the means of all various locations in each of the six Governorates, respectively. Again, the mean, median, minimum, maximum, and range values of CSE and DUH locations exhibit the highest and lowest TTHM values, respectively. The highest and lowest mean values of TTHM were found, as previously shown, for CSE and DUH, respectively. The values of $\boldsymbol{I}$ samples are significantly higher in CSW location and to a lesser extent in CSO and DUH locations, in addition to GAH Governorate. The values of $\boldsymbol{O}$ samples are significantly higher at CQB, CSH, CSL, and JOY; in addition to CKF, CSE, FAR, FRI, and the five Governorates (GCA, GFA, GHA, GJA, and GMK) with less extent.

In 1988, Ali et al. [16] found that TTHMs in the drinking water of Kuwait (from rooftop storage tanks) averaged 25.6 $\pm 9.1 \mu \mathrm{g} / \mathrm{L}$ with a maximum recorded value of $50.5 \mu \mathrm{g} / \mathrm{L}$. In the present study, the mean value of $\boldsymbol{I}$ samples was found to be $45.5 \pm 2.6 \mu \mathrm{g} / \mathrm{L}$ (for same desalination plants) with the highest recorded value of $90.5 \mu \mathrm{g} / \mathrm{L}$. This finding shows that TTHM levels in Kuwait's drinking water have dramatically 

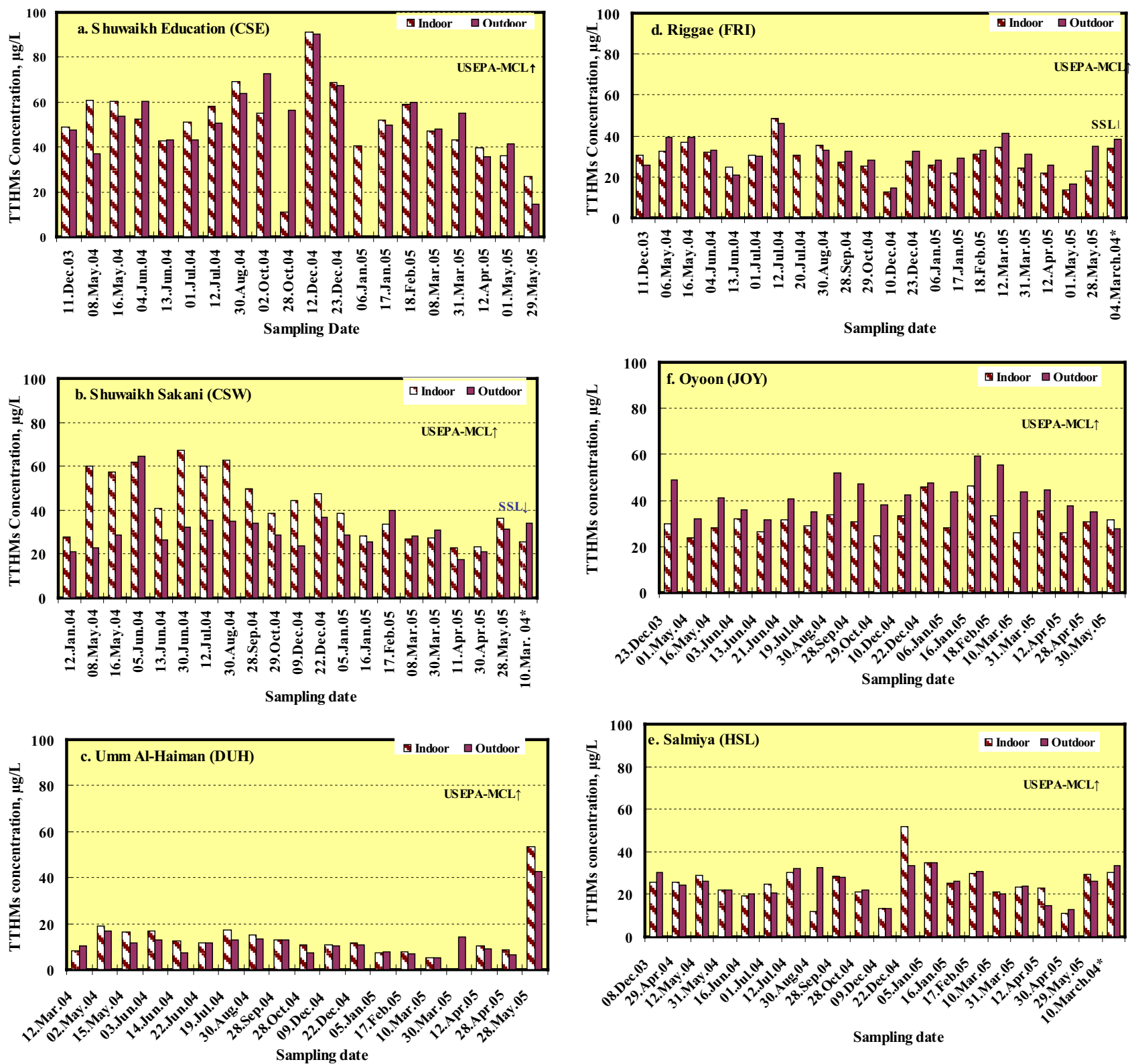

Fig. (2). Variation of TTHMs in indoor $(\boldsymbol{I})$ and outdoor $(\boldsymbol{O})$ samples with sampling date for high-frequency sampling locations. $(S S L=S e c$ ondary Sampling Location).

increased during the 17 years that have passed between the two studies. This increase may be attributed to several factors mentioned above, but certainly the increase of organics in the Arabian Gulf seawater as a result of the Gulf crises that occurred during this period is a reasonable factor.

The results presented above show that significant variation exists in TTHM levels either with the sampling date for each individual location (building) or from one location to another. Also, it varies between $\boldsymbol{I}$ and $\boldsymbol{O}$ points of the same building. These variations can be explained in view of the fact that THM levels in chlorinated drinking water, as mentioned previously, depends on several factors including chlorine dosage, residual chlorine in the distribution system and its contact time, temperature, $\mathrm{pH}$, precursor concentrations, etc. [25]. These factors may vary from one location to another and from one date to another, as well as from one desalination plant to another [16]. Fig. (4) shows the relationship between the levels of TTHMs with each of residual chlorine levels, sampling temperature, and $\mathrm{pH}$. In accordance with the results of previous studies [6, 12], Fig. (4) shows good correlations between residual chlorine and TTHMs. It is evident that the higher recorded values of TTHMs in $\boldsymbol{O}$ samples of CSW location are correlated to the lower values of residual chlorine. Also, the lower values of TTHMs in $\boldsymbol{I}$ samples of same location are significantly correlated to the higher values of residual chlorine. Temperature may show some correlations while $\mathrm{pH}$ has no effect as there is no significant change in its value during the study period. In addition, the residence time of chlorine also plays an important 
Table 3. TTHMs Concentration $(\mu \mathrm{g} / \mathrm{L})$ of Indoor $(I)$ and Outdoor $(O)$ Samples at Different Dates of Collection

A- Individual Locations with High Frequency Sampling (Collection Times 7-9)

\begin{tabular}{|c|c|c|c|c|c|c|c|c|c|c|c|}
\hline \multicolumn{4}{|c|}{ 1. Kifan Location(CKF) } & \multicolumn{4}{|c|}{ 2. Qibla Location (CQB) } & \multicolumn{4}{|c|}{ 3. Shuwaikh Health Location (CSH) } \\
\hline Location $^{(1)}$ & Date & $\mathbf{I}$ & $\mathbf{O}$ & Location $^{(1)}$ & Date & $\mathbf{I}$ & $\mathbf{O}$ & Location $^{(1)}$ & Date & $\mathbf{I}$ & $\mathbf{O}$ \\
\hline CKF-A & 10.Jan.04 & 26.7 & 38.4 & CQB-A & 15.Jan.04 & 10.8 & 22.3 & CSH-A & 04.Feb.04 & 31.7 & - \\
\hline CKF-A & 11.May.04 & 29.7 & 30.3 & CQB-A & 29.May.04 & 8.0 & 21.1 & CSH-A & 26.Sep.04 & 21.9 & 19.8 \\
\hline CKF-A & 18.Feb.05 & 44.3 & 43.4 & CQB-A & 12.Dec.04 & 14.0 & 14.7 & CSH-A & 18.Feb.05 & 36.5 & 42.9 \\
\hline CKF-A & 07.Mar.05 & 59.3 & 58.5 & CQB-A & 18.Feb.04 & 14.3 & 37.7 & CSH-A & 08.Mar.05 & 14.9 & 8.1 \\
\hline CKF-A & 30.Mar.05 & 39.8 & 45.8 & CQB-A & 06.Mar.05 & 21.8 & 38.8 & CSH-A & 30.Mar.05 & 26.6 & 40.9 \\
\hline CKF-A & 11.Apr.05 & 44.5 & 43.1 & CQB-A & 31.Mar.05 & 22.6 & 30.2 & CSH-A & 10.Apr.05 & 14.6 & 23.9 \\
\hline CKF-A & 30.Apr.05 & 26.5 & 28.2 & CQB-A & 10.Apr.05 & 9.0 & 11.1 & CSH-A & 30.Apr.05 & 14.7 & 19.8 \\
\hline CKF-A & 28.May.05 & 53.1 & 51.4 & CQB-A & 28.Apr.05 & 16.3 & 22.0 & CSH-A & 28.May.05 & 15.0 & 31.6 \\
\hline \multirow{2}{*}{\multicolumn{4}{|c|}{ CKF-B }} & CQB-A & 28.May.05 & 34.0 & 52.1 & & & & \\
\hline & & & & CQB-B & 17.Mar. 04 & 10.8 & 22.3 & & & & \\
\hline \multicolumn{4}{|c|}{ 4. Sulaibekhat Location (CSL) } & \multicolumn{4}{|c|}{ 5. Sorra Location (CSO) } & \multicolumn{4}{|c|}{ 6. Ardiya Location (FAR) } \\
\hline CSL-A & 06.Dec.03 & 29.4 & 39.9 & CSO-A & 24.Dec.03 & 23.7 & 25.4 & FAR-A & 26.Dec.03 & 32.8 & 48.0 \\
\hline CSL-A & 01.May.04 & 31.5 & 26.6 & CSO-A & 29.Apr.04 & 19.8 & 20.9 & FAR-A & 11.May.04 & 46.2 & 38.8 \\
\hline CSL-A & 18.Feb.05 & 27.8 & 45.4 & CSO-A & 07.Mar.05 & 17.4 & 17.1 & FAR-A & 18.Feb.05 & 34.2 & 39.7 \\
\hline CSL-A & 10.Mar.05 & 17.8 & 26.7 & CSO-A & 30.Mar.05 & 17.8 & 14.7 & FAR-A & 07.Mar.05 & 29.6 & 36.8 \\
\hline CSL-A & 31.Mar.05 & 21.4 & 42.5 & CSO-A & 10.Apr.05 & 19.6 & 18.5 & FAR-A & 30.Mar.05 & 28.6 & 29.5 \\
\hline CSL-A & 10.Apr.05 & 17.8 & 20.8 & CSO-A & 28.Apr.05 & 18.4 & 17.4 & FAR-A & 11.Apr.05 & 20.2 & 24.1 \\
\hline CSL-A & 28.Apr.05 & 12.9 & 15.9 & CSO-A & 29.May.05 & 71.4 & 50.5 & FAR-A & 28.Apr.05 & 19.4 & 14.1 \\
\hline CSL-A & 30.May.05 & 20.4 & 32.6 & CSO-B & 28.Feb.04 & 19.3 & 29.7 & FAR-A & 28.May.05 & 33.6 & 23.7 \\
\hline & & & & & & & & FAR-B & March.04 & 35.1 & NA \\
\hline
\end{tabular}

B. Low Frequency Sampling Locations within Each of the Individual Governorates

\begin{tabular}{|c|c|c|c|c|c|c|c|c|c|c|c|}
\hline \multicolumn{4}{|c|}{ 1. Capital Gov. (GCA) } & \multirow{2}{*}{$\frac{\text { Location }^{(1)}}{\text { CFH-B }}$} & \multirow{2}{*}{$\begin{array}{c}\text { Date } \\
\text { 24.Feb.04 }\end{array}$} & \multirow{2}{*}{$\frac{\text { I }}{30.4}$} & \multirow{2}{*}{$\frac{\mathbf{O}}{38.3}$} & \multirow{2}{*}{$\frac{\text { Location }^{(1)}}{\text { DAH-A }}$} & \multirow{2}{*}{$\begin{array}{c}\text { Date } \\
\text { 15.May.04 }\end{array}$} & \multirow{2}{*}{$\frac{\mathbf{I}}{20.1}$} & \multirow{2}{*}{$\begin{array}{c}\mathbf{O} \\
14.8\end{array}$} \\
\hline Location $^{(1)}$ & Date & $\mathbf{I}$ & $\mathbf{O}$ & & & & & & & & \\
\hline CAA-A & 12.Jan.04 & 24.5 & 29.5 & CKD-A & 10.Jan.04 & 24.7 & 32.1 & DAH-B & 12.Mar.04 & 55.2 & 16.1 \\
\hline CAA-A & 28.May.04 & 36.1 & 28.9 & CKD-A & 11.May.04 & 33.4 & 34.6 & DDH-A & 14.Feb.04 & 24.6 & 25.2 \\
\hline CAA-A & 11.Dec.04 & 33.5 & 50.5 & CKD-B & 24.Feb.04 & 37.3 & 29.2 & DDH-A & 22.Sep.04 & 16.4 & 13.2 \\
\hline CAA-B & 28.Feb.04 & 31.6 & 39.6 & CMN-A & 15.Jan.04 & 19.1 & 28.2 & DFH-A & 10.Dec.03 & 13.3 & 19.7 \\
\hline CAD-A & 26.Dec. 03 & 24.5 & 49.4 & CMN-A & 28.May.04 & 23.5 & 30.7 & DFH-A & 02.May.04 & 12.1 & 11.5 \\
\hline CAD-A & 29.Apr.04 & 16.5 & 24.2 & CMR-A & 15.Jan.04 & 17.8 & 28.3 & DFH-B & 12.Mar.04 & 16.5 & 18.3 \\
\hline CAD-B & 24.Feb.04 & 34.3 & 40.1 & CMR-A & 29.May.04 & 21.9 & 25.2 & DFN-A & 22.Feb.04 & 11.6 & 12.4 \\
\hline CBQ-A & 25.Jan.04 & 34.2 & 27.2 & CQD-A & 26.Dec.03 & 28.0 & 41.1 & DFN-A & 22.Sep.04 & 28.1 & 14.3 \\
\hline CBQ-A & 31.May.04 & 19.5 & 29.4 & CQD-A & 12.May.04 & 30.9 & 41.6 & DHD-A & 14.Feb.04 & 29.3 & 22.8 \\
\hline CBQ-B & 17.Mar.04 & 31.0 & 30.1 & CQD-A & 11.Dec.04 & 53.8 & 62.0 & DHD-A & 22.sep.04 & 30.3 & 16.0 \\
\hline CDH-A & 24.Dec.03 & 42.9 & 44.9 & CQD-B & 28.Feb.04 & 29.7 & 30.9 & DJA-A & 14.Feb.04 & 20.5 & 21.4 \\
\hline CDH-A & 01.May.04 & 19.6 & 28.2 & CRD-A & 24.Dec. 03 & 11.5 & 56.1 & DJA-A & 22.sep.04 & 16.2 & 17.3 \\
\hline CDH-B & 16.Mar.04 & NA & 31.9 & CRD-A & 29.Apr.04 & 11.6 & 22.6 & DMH-A & 22.Feb.04 & 29.6 & 29.5 \\
\hline CDM-A & 15.Jan.04 & 15.8 & 26.9 & CSI-A & 04.Feb.04 & 33.5 & 43.7 & DMH-A & 21.Sep.04 & 11.9 & 16.0 \\
\hline CDM-A & 28.May.04 & 10.1 & 28.0 & CSI-A & 26.Sep.04 & 19.9 & 19.8 & DMN-A & 22.Feb.04 & 11.7 & 9.9 \\
\hline CDM-A & 11.Dec.04 & 41.6 & 30.8 & CSM-A & 12.Jan.04 & 19.8 & 23.7 & DMN-A & 21.Sep.04 & 31.6 & 12.9 \\
\hline CDM-B & 28.Feb.04 & 37.0 & 43.1 & CSM-A & 28.May.04 & 27.3 & 26.3 & DRG-A & 14.Feb.04 & 23.5 & 21.9 \\
\hline CDS-A & 15.Jan.04 & 22.0 & 29.1 & CSM-B & 24.Feb.04 & 27.6 & 39.4 & DRG-A & 12.Sep.04 & 45.1 & 65.2 \\
\hline CDS-A & 29.May.04 & 28.7 & 27.1 & CYA-A & 04.Feb.04 & NA & 45.9 & DRG-B & 12.Mar.04 & 19.9 & 12.6 \\
\hline CDS-B & 10.Mar.04 & 31.9 & 33.2 & CYA-A & 26.Sep.04 & 18.7 & 18.8 & DSB-A & 22.Feb.04 & 16.4 & 12.6 \\
\hline CDY-A & 15.Jan.04 & 26.8 & 25.5 & \multicolumn{4}{|c|}{ 2. Ahmadi Gov. (GAH } & DSB-A & 21.Sep.04 & 18.0 & 13.6 \\
\hline CDY-A & 29.May.04 & 27.4 & 25.1 & DAD-A & 26.Dec.03 & 13.1 & 16.9 & \multicolumn{4}{|c|}{ 3. Farwaniya Gov. (GFA) } \\
\hline CDY-B & 28.Feb.04 & 21.7 & 27.4 & DAD-A & 15.May.04 & 10.5 & 11.4 & FAK-A & 25.Jan.04 & 29.9 & 36.3 \\
\hline CFH-A & 31.May.04 & 30.3 & 25.2 & DAD-B & 12.Mar.04 & 12.4 & 11.2 & FAK-A & 12.Jun.04 & 20.1 & 26.4 \\
\hline CFH-A & 11.Dec.04 & 53.4 & 31.8 & DAH-A & 26.Dec.03 & 18.5 & 15.5 & FAK-B & 03.Mar.04 & 25.6 & $\mathrm{NA}$ \\
\hline
\end{tabular}




\begin{tabular}{|c|c|c|c|c|c|c|c|c|c|c|c|}
\hline \multicolumn{4}{|c|}{ GFA, Contd.... } & \multirow{2}{*}{$\begin{array}{c}\text { Location }^{(\mathbf{1})} \\
\text { HHW-A }\end{array}$} & \multirow{2}{*}{$\begin{array}{c}\text { Date } \\
\text { 08.Dec.03 }\end{array}$} & \multirow{2}{*}{$\frac{\mathbf{I}}{23.3}$} & \multirow{2}{*}{$\frac{\mathbf{O}}{32.0}$} & \multirow{2}{*}{$\begin{array}{c}\text { Location }^{(1)} \\
\text { JQA-A }\end{array}$} & \multirow{2}{*}{$\begin{array}{c}\text { Date } \\
\text { 11.Feb.04 }\end{array}$} & \multirow{2}{*}{$\frac{\text { I }}{65.9}$} & \multirow{2}{*}{$\begin{array}{c}\mathbf{O} \\
55.2\end{array}$} \\
\hline Location $^{(1)}$ & Date & $\mathbf{I}$ & $\mathbf{O}$ & & & & & & & & \\
\hline FAN-A & 25.Jan.04 & 22.2 & 33.5 & HHW-A & 29.Apr.04 & 28.9 & 34.2 & JQA-A & 21.Jun.04 & 44.9 & 30.4 \\
\hline FAN-A & 12.Jun.04 & 29.7 & 30.2 & HHW-B & 12.Mar.04 & 15.45 & 14.1 & JQA-A & 16.Dec.04 & 47.3 & 54.7 \\
\hline FFD-A & 26.Jan.04 & 25.4 & 39.9 & HJB-A & 12.Jan.04 & 19.5 & 20.9 & JSL-A & 24.Dec.04 & 28.5 & 40.8 \\
\hline FFD-A & 12.Jun.04 & 31.8 & 28.7 & HJB-A & 29.Apr.04 & 32.9 & 16.6 & JSL-A & 01.May.04 & 30. & 25.4 \\
\hline FFR-A & 25.Jan.04 & 28.7 & 39.7 & HMS-A & 10.Jan.04 & 31.5 & 29.4 & JSL-A & 16.Dec.04 & 54.6 & 51.0 \\
\hline FFR-A & 12.Jun.04 & 19.9 & 24.5 & HMS-A & 12.May.04 & 22.2 & 18.7 & JTA-A & 11.Feb.04 & 43.0 & 58.2 \\
\hline FFR-B & 02.Mar.04 & 54.5 & 61.8 & HMS-A & 15.Mar.05 & 17.2 & 15.4 & JTA-A & 21.Jun.04 & 23.9 & 32.1 \\
\hline FJS-A & 26.Jan.04 & 34.5 & 34.0 & HRM-A & 25.Jan.04 & 27.2 & 30.7 & JTA-A & 16.Dec.04 & 35.0 & 41.4 \\
\hline FJS-A & 12.Jun.04 & 28.4 & 27.5 & HRM-A & 31.May.04 & 21.0 & 24.4 & JWA-A & 11.Feb.04 & 8.4 & 55.6 \\
\hline FOM-A & 25.Jan.04 & 33.9 & 41.5 & HRM-B & 10.Mar.05 & 24.4 & 27.5 & JWA-A & 21.Jun.04 & NA & 34.8 \\
\hline FOM-A & 11.Jun.04 & 39.0 & 26.4 & HSH-A & 26.Dec.03 & 27.4 & 41.2 & JWA-A & 16.Dec.04 & 6.8 & 45.2 \\
\hline FRB-A & 25.Jan.04 & 37.2 & 38.3 & HSH-A & 12.May.04 & 28.3 & 33.3 & \multicolumn{4}{|c|}{ Mubarak Al-Kabeer (GMK) } \\
\hline FRB-A & 11.Jun.04 & 30.0 & 25.8 & HSW-A & 10.Dec.03 & 24.2 & 29.0 & MAD-A & 26.Dec.03 & 37.1 & 33.8 \\
\hline FRB-B & 16.Mar.04 & 29.3 & 39.4 & HSW-A & 03.May.04 & 20.1 & 25.8 & MAD-A & 15.May.04 & 25.5 & 27.7 \\
\hline FRH-A & 26.Jan.04 & 32.7 & 37.1 & \multicolumn{4}{|c|}{ 5. Jahra Gov. (GHA) } & MMK-A & 26.Sep.04 & 18.7 & 17.0 \\
\hline FRH-A & 11.Jun.04 & 29.4 & 24.2 & JGH-A & 23.Dec.03 & 35.3 & 37.7 & MMS-A & 26.Dec.03 & 27.23 & 46.0 \\
\hline FRH-B & 03.Mar.04 & 35.4 & 41.5 & JGH-A & 01.May.04 & 31.8 & 31.3 & MMS-A & 15.May.04 & 29.0 & 25.2 \\
\hline FSK-A & 25.Jan.04 & 28.6 & 38.2 & JGH-A & 10.Dec. 03 & 21.0 & 27.9 & MQR-A & 14.Feb.04 & 27.9 & $\mathrm{NA}$ \\
\hline FSK-A & 12.Jun.04 & 21.1 & 23.4 & JGH-B & 02.Mar.04 & 37.8 & 37.7 & MQR-A & 26.Sep.04 & 19.6 & 19.1 \\
\hline FSK-B & 12.Mar.04 & 34.5 & 33.0 & JNA-A & 11.Feb.04 & 56.2 & 56.7 & MQU-A & 14.Feb.04 & 19.4 & 19.0 \\
\hline FSN-A & 26.Jan.04 & 35.5 & 34.5 & JNA-A & 21.Jun.04 & 24.9 & 30.9 & MQU-A & 26.Sep.04 & 17.5 & 14.7 \\
\hline FSN-A & 12.Jun.04 & 29.0 & 28.5 & JNA-A & 16.Dec.04 & 50.3 & 39.6 & MSA-A & 10.Dec.03 & 9.9 & 14.5 \\
\hline \multicolumn{4}{|c|}{ 4. Hawalli Gov. (GHA) } & JNM-A & 11.Feb.04 & 48.0 & 50.8 & MSA-A & 03.May.04 & 14.0 & 18.7 \\
\hline HBY-A & 10.Jan.04 & 28.2 & 33.1 & JNM-A & 21.Jun.04 & 26.4 & 32.7 & & & & \\
\hline HBY-A & 12.May.04 & 23.4 & 26.1 & JNM-A & 16.Dec.04 & 34.7 & 41.7 & & & & \\
\hline
\end{tabular}

${ }^{11)} \mathrm{A}$ and $\mathrm{B}-$ added to location codes indicate primary and secondary locations, respectively. NA- not analyzed.

role for affecting TTHM variation, which depends on the water flow rate inside the building. As mentioned previously, we know that water comes to the indoor tap from the rooftop storage tank that is fed from an underground reservoir. This means that the outdoor water, which comes directly from the distribution system, stays in the reservoir and rooftop tank for variable periods depending on the water flow inside the building. This situation may add more clues to explain the results of this study.

The chlorination of fresh water produces CFM as a major compound among THMs. Krasner et al. [29] reported that CFM is usually the most prevalent THM formed in US drinking water. In drinking water produced by the desalination of seawater, where bromide is found in abundance, brominated THMs (specifically BFM) are the dominant species. Formation of these species is dependent on concentration of $\mathrm{Br}^{-}$ion in addition to the factors mentioned previously. Fig. (5) shows the variation of the mean values of THM species in the various high-frequency sampling locations, while Fig. (6) illustrates the means of minimum and maximum percentages of these species in the drinking water in Kuwait. In agreement with previous studies [16-22], we found that brominated THMs were the dominant species and BFM is the most dominant one. The minimum and maxi- mum percentage were found to be 59.0 and $93.5 \%$ for BFM, 5.0 and 30.0 for CDBM, 0.5 and $9.7 \%$ for BDCM, and 0.0 and $2.9 \%$ for CFM, respectively. On the other hand, CFM and BFM were detected in $79 \%$ and $100 \%$ of samples with the highest values of 0.5 and $82.3 \mu \mathrm{g} / \mathrm{L}$, respectively. BDCM and DBCM were detected in $100 \%$ of samples with the highest values of 2.31 and $13.94 \mu \mathrm{g} / \mathrm{L}$, respectively.

A survey of the literature indicates that the occurrence of THM in chlorinated water may vary strongly with season and geographical location of the distribution system. In temperate environments, THM levels in drinking water are strongly affected by seasonal conditions [12, 13, 30-34]. Several studies have reported higher concentrations of THMs in the summer and fall compared to winter [13, 29, 32]. Moreover, higher THMs concentrations have been observed particularly in the extremities of water distribution systems, especially in the summer months $[12,31]$. These findings are explained in view of that in the winter months, THM concentrations are lower due to lower water temperature and NOM. In these conditions, the chlorine demand is lower, therefore, the chlorine dose required to maintain adequate residual in the distribution system is also less important. The type of raw water also affects THM levels, which are usually higher in desalinated water due to the increase of 
Table 4. Statistical Summary of TTHMs Concentrations $(\mu \mathrm{g} / \mathrm{L})$ for Indoor (I) and Outdoor (O) Samples Collected During the Time Period from December 2003 to May 2005

\begin{tabular}{|c|c|c|c|c|c|c|c|c|c|c|c|c|c|}
\hline Sampling & No. of Analyzed & \multicolumn{2}{|c|}{ Mean } & \multicolumn{2}{|c|}{ SD } & \multicolumn{2}{|c|}{ Median } & \multicolumn{2}{|c|}{ Min. } & \multicolumn{2}{|c|}{ Max. } & \multicolumn{2}{|c|}{ Range } \\
\hline Location $^{a}$ & Samples ${ }^{b}$ & $I$ & $O$ & $I$ & $\boldsymbol{O}$ & $I$ & $O$ & $I$ & $O$ & $I$ & $O$ & $I$ & $O$ \\
\hline $\mathrm{CKF}^{\mathrm{c}}$ & $8(8)$ & 40.5 & 42.4 & 12.2 & 10.1 & 42.1 & 43.3 & 26.5 & 28.2 & 59.3 & 58.5 & 32.8 & 30.2 \\
\hline $\mathrm{CQB}^{\mathrm{c}}$ & $9(9)$ & 16.8 & 27.8 & 8.2 & 13.1 & 14.3 & 22.3 & 8.0 & 11.1 & 34.0 & 52.1 & 26.0 & 41.0 \\
\hline $\mathrm{CSE}^{\mathrm{c}}$ & $20(19)$ & 50.7 & 52.2 & 16.8 & 16.1 & 51.6 & 50.8 & 11.0 & 14.4 & 91.0 & 90.5 & 80.0 & 76.0 \\
\hline $\mathrm{CSH}^{\mathrm{c}}$ & $8(8)$ & 22.0 & 26.7 & 8.7 & 12.5 & 18.4 & 23.9 & 14.6 & 8.1 & 36.5 & 42.9 & 21.9 & 34.8 \\
\hline $\mathrm{CSL}^{\mathrm{c}}$ & $8(8)$ & 22.4 & 31.3 & 6.5 & 10.6 & 20.9 & 29.7 & 12.9 & 15.9 & 31.5 & 45.4 & 18.6 & 29.6 \\
\hline $\mathrm{CSO}^{\mathrm{c}}$ & $7(7)$ & 25.9 & 23.5 & 18.5 & 12.4 & 19.5 & 18.5 & 17.4 & 14.7 & 71.4 & 50.5 & 53.9 & 35.7 \\
\hline $\mathrm{CSW}^{\mathrm{c}}$ & $20(20)$ & 42.8 & 30.6 & 14.7 & 9.9 & 39.6 & 28.8 & 22.8 & 17.3 & 67.2 & 64.6 & 44.5 & 47.4 \\
\hline $\mathrm{DUH}^{\mathrm{c}}$ & $18(19)$ & 14.2 & 12.1 & 10.5 & 8.0 & 11.7 & 10.7 & 5.2 & 5.0 & 53.6 & 42.6 & 48.4 & 37.7 \\
\hline $\mathrm{FAR}^{\mathrm{c}}$ & $8(8)$ & 30.6 & 31.9 & 8.5 & 11.0 & 31.2 & 33.2 & 19.4 & 14.1 & 46.2 & 48.0 & 26.8 & 33.9 \\
\hline $\mathrm{FRI}^{\mathrm{c}}$ & $21(20)$ & 28.1 & 30.7 & 7.9 & 7.8 & 27.7 & 31.7 & 12.8 & 14.5 & 48.5 & 46.2 & 35.7 & 31.7 \\
\hline $\mathrm{HSL}^{\mathrm{c}}$ & $20(20)$ & 25.1 & 24.7 & 8.8 & 6.6 & 24.9 & 25.2 & 11.0 & 12.8 & 51.8 & 35.0 & 40.8 & 22.2 \\
\hline $\mathrm{JOY}^{\mathrm{c}}$ & $20(20)$ & 31.3 & 42.0 & 6.0 & 8.2 & 30.9 & 41.8 & 23.6 & 27.9 & 46.2 & 59.5 & 22.6 & 31.6 \\
\hline $\mathrm{GCA}^{\mathrm{d}}$ & $45(47)$ & 27.7 & 33.1 & 9.6 & 9.4 & 27.6 & 30.1 & 10.1 & 18.8 & 53.8 & 62.0 & 43.7 & 43.3 \\
\hline $\mathrm{GAH}^{\mathrm{d}}$ & $26(26)$ & 21.4 & 18.2 & 10.8 & 10.7 & 18.2 & 15.7 & 10.5 & 9.9 & 55.2 & 65.2 & 44.8 & 55.3 \\
\hline $\mathrm{GFA}^{\mathrm{d}}$ & $25(25)$ & 30.6 & 33.9 & 7.2 & 8.4 & 29.7 & 33.7 & 19.9 & 23.4 & 54.5 & 61.8 & 34.7 & 38.4 \\
\hline $\mathrm{GHA}^{\mathrm{d}}$ & $16(16)$ & 24.9 & 27.3 & 4.7 & 7.1 & 24.3 & 28.4 & 15.5 & 14.1 & 32.9 & 41.2 & 17.5 & 27.1 \\
\hline GJA $^{\mathrm{d}}$ & $21(22)$ & 35.9 & 41.4 & 15.1 & 10.4 & 35.0 & 40.2 & 6.8 & 25.4 & 65.9 & 58.2 & 59.1 & 32.7 \\
\hline $\mathrm{GMK}^{\mathrm{d}}$ & $11(10)$ & 22.3 & 23.6 & 7.8 & 10.0 & 19.6 & 19.0 & 9.9 & 14.5 & 37.1 & 46.0 & 27.2 & 31.6 \\
\hline
\end{tabular}

${ }^{\mathrm{a}}$ As shown in Fig. (1), ${ }^{\mathrm{b}} \mathrm{I}(\mathrm{O}),{ }^{\mathrm{c}}$ all samples are collected from this location only, ${ }^{\mathrm{d}}$ samples are collected from various locations within the Governorate.

NOM and DBP precursors in the main source of desalination (seawater).

Fig. (7) shows the seasonal variations of TTHMs between six of the twelve individual locations (CSE, CSW, DUH, FRI, HSL and JOY) of the highest collection times; 19 to 21 . Various different seasonal variations are shown either between the locations or between $\boldsymbol{I}$ and $\boldsymbol{O}$ samples. In both $\boldsymbol{I}$ and $\boldsymbol{O}$ samples, three and one location exhibit highest values in summer and spring, respectively. On the other hand, TTHMs are the highest in fall (two locations) and spring (one location) for $\boldsymbol{I}$ samples, which are found in one location in each of winter, spring, and fall for $\boldsymbol{O}$ samples. Other loca- tions and Governorates show different patterns. No specific season is prevailing.

In the Arabian Gulf region in general and Kuwait in particular, climatic changes during the year are specific and considerably different as compared to other geographic regions. It is not fair to consider or differentiate the four seasons as usual, but instead, the conditions of only winter and summer are the mostly common. Winters are short (December to March) and fairly cold $\left(-2-28^{\circ} \mathrm{C}\right)$, whereas summers are relatively long (April to November) but generally hot $\left(24-55^{\circ} \mathrm{C}\right)$. Consequently, differences in water temperature
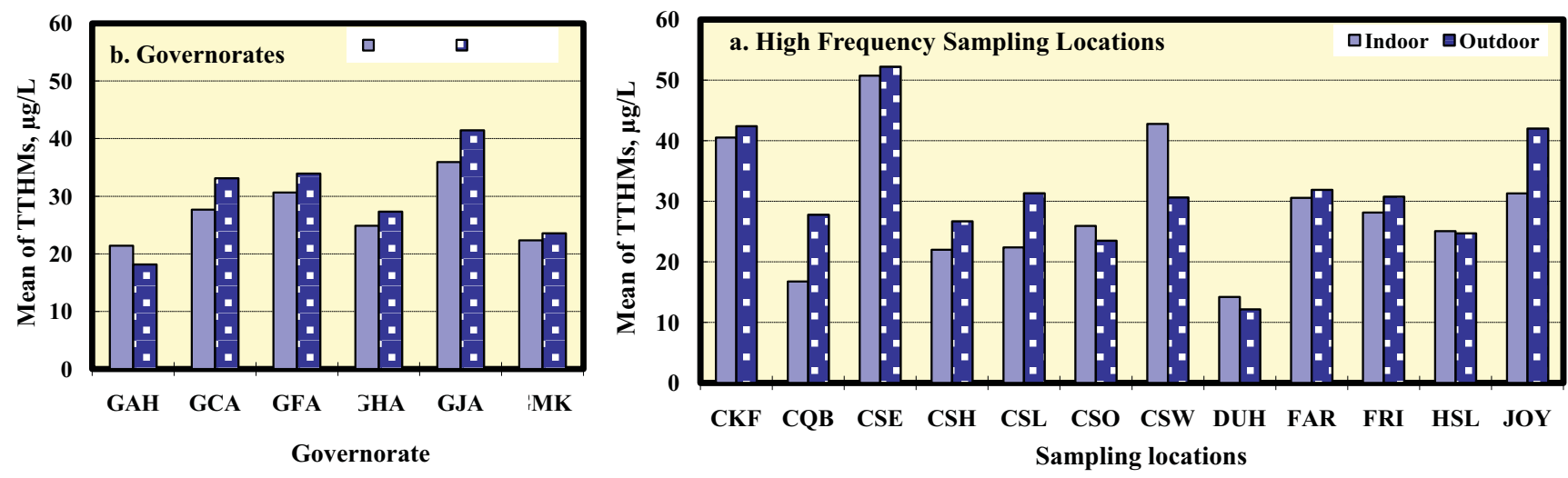

Fig. (3). Variation of the mean value of TTHMs with various locations (high frequency sampling) and Governorates. 

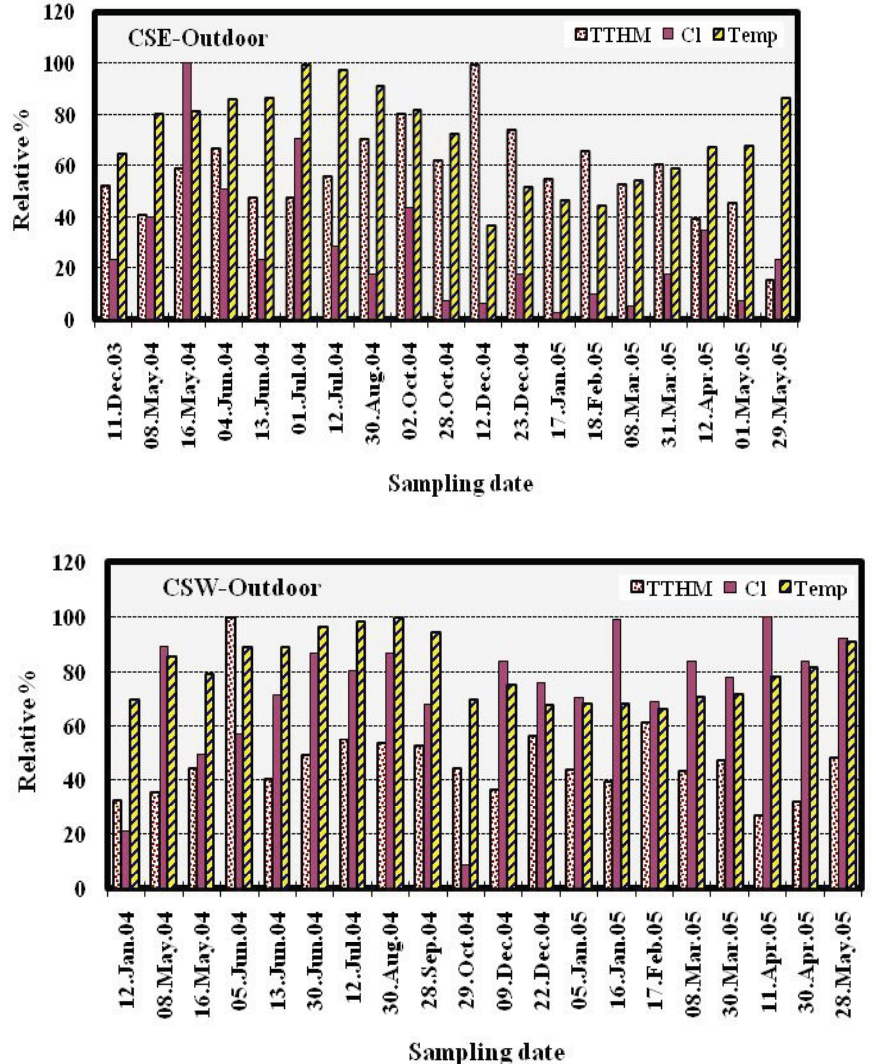
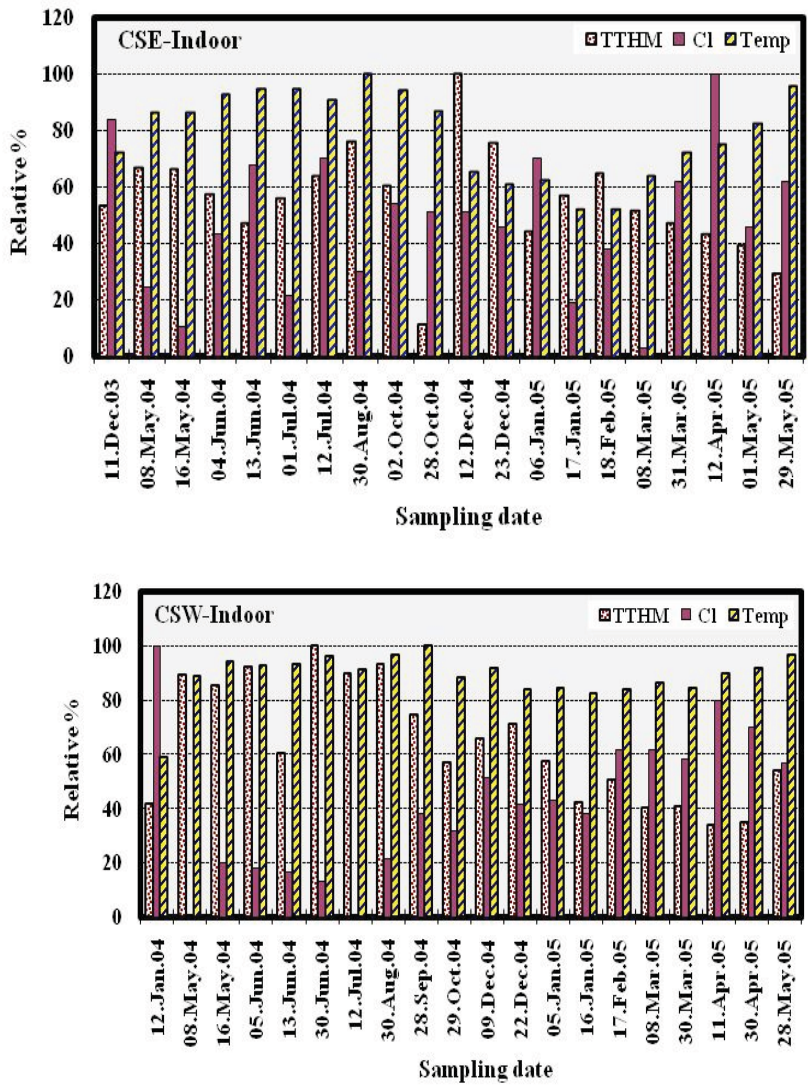

Fig. (4). Relative measurement of TTHMs, free residual chlorine and temperature for CSE and CSW sampling locations (the highest values of each are represented as $100 \%)$.

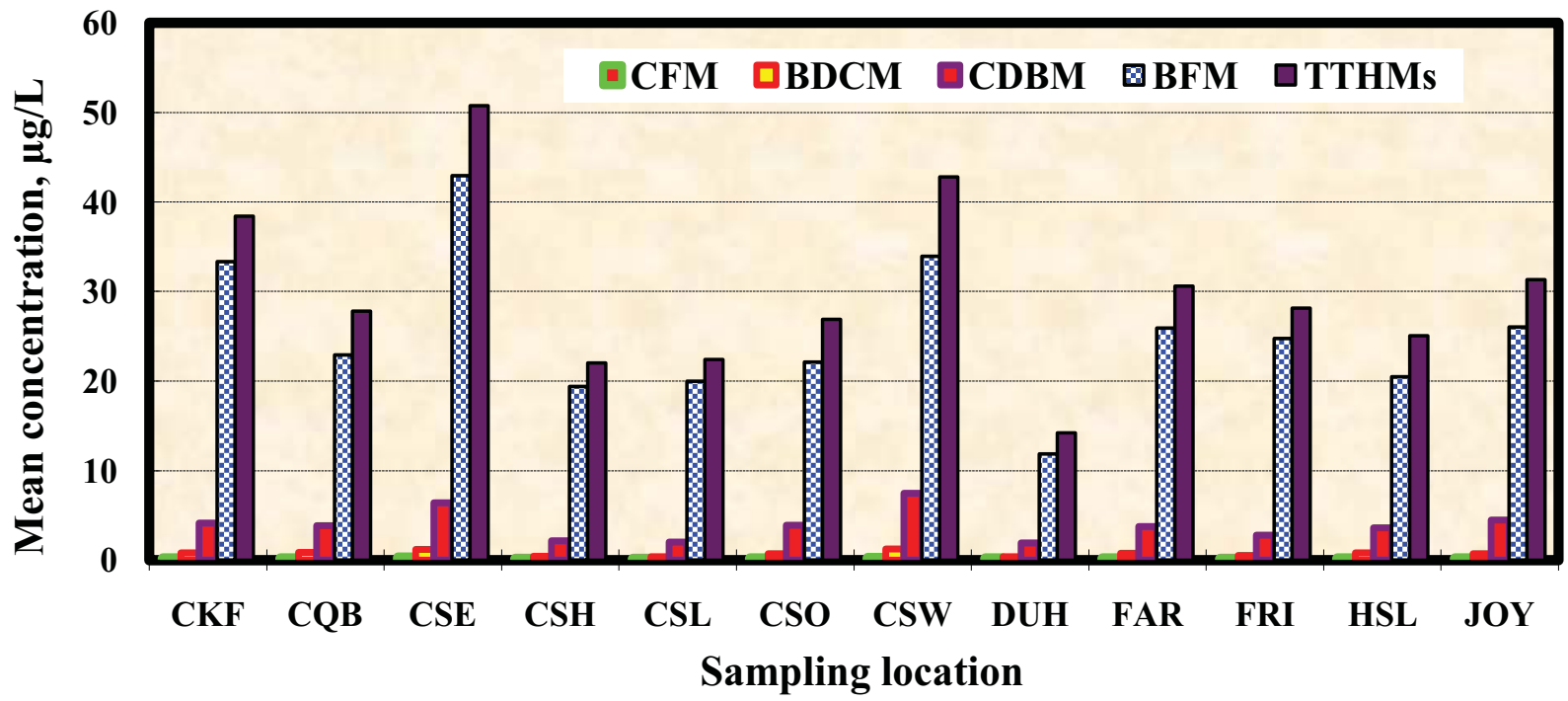

Fig. (5). Variation of the mean values of THM species with various high frequency sampling locations (7 to 21 collection times).

between those periods can be greater than $25^{\circ} \mathrm{C}$. This factor may contribute to significant changes in water quality and, depending on operational adjustments during the treatment processes and chlorine disinfection, may also contribute to seasonal changes in THMs over the course of the year. Based on this last consideration, as shown in Fig. (8), significant seasonal variations were found. These variations differ with various individual sampling locations and within 


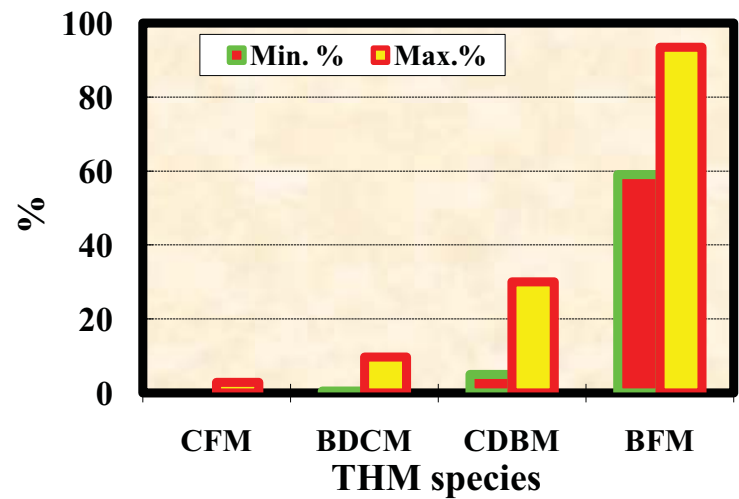

Fig. (6). Variation of the minimum and maximum percentages of THM species during the study period. the Governorates. Variation was much higher in winter than summer in seven locations (CKF, CSE, CSH, CSL, FAR, HSL, and JOY) and all six of the Governorates. On the other hand, TTHMs were higher in summer in four locations (CSO, CSW, DUH, and FRI), while there was no appreciable difference between the two seasons in one location (CQB). In winter, the outdoor levels of TTHMs were mostly higher than those of the indoor for most of locations and Governorates, which were approximately the same in summer. The lowest levels of TTHMs in both winter and summer were seen at DUH location and GAH Governorate, while the highest levels were shown by CSE location and GJA Governorate. In contrast to previous studies 12, 13, 29, $31,32]$, the results of this study show that higher values of TTHMs were present in the winter This can be explained by

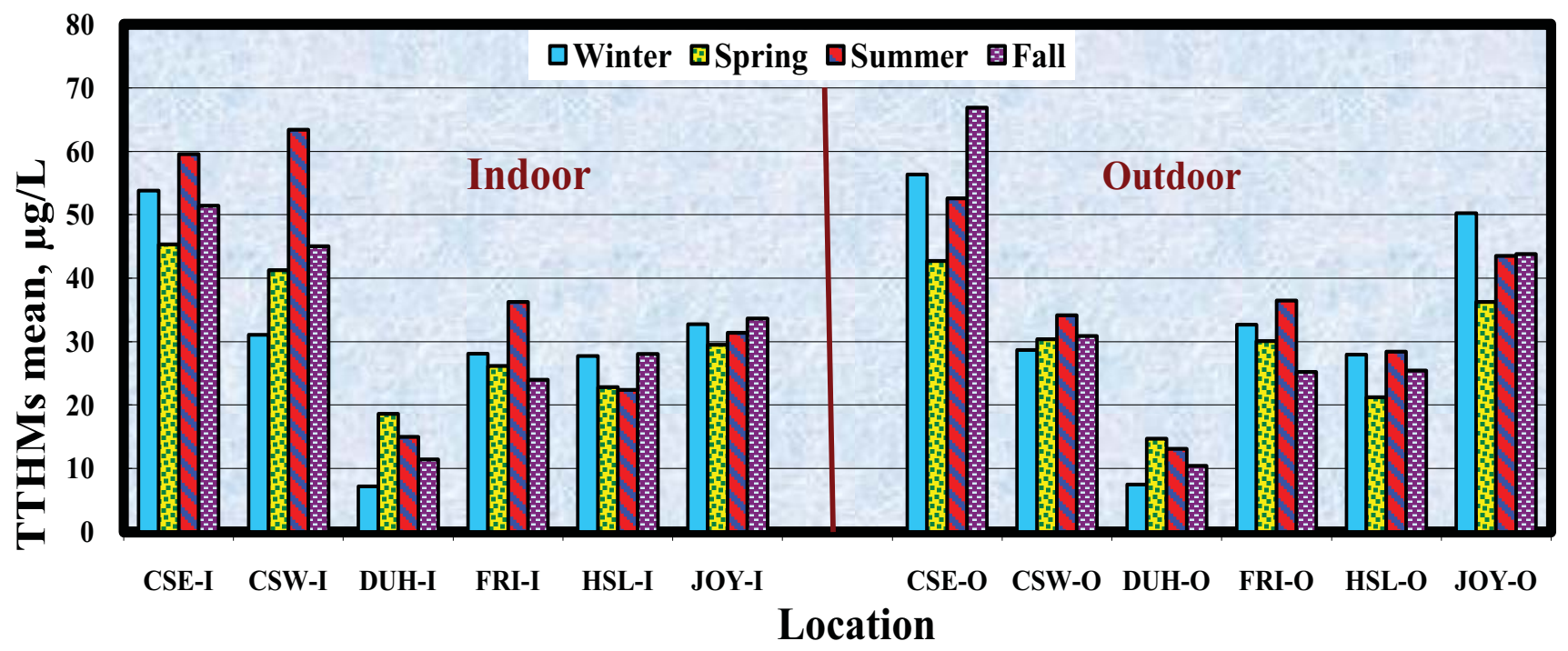

Fig. (7). Seasonal variation of TTHMs in the drinking water of the six highest frequency sampling locations - 19 to 21 collections (Winter: December 22 to March 21; Spring: March22to June 21; Summer: June 22 to September 21; Fall: September22 to December 21).

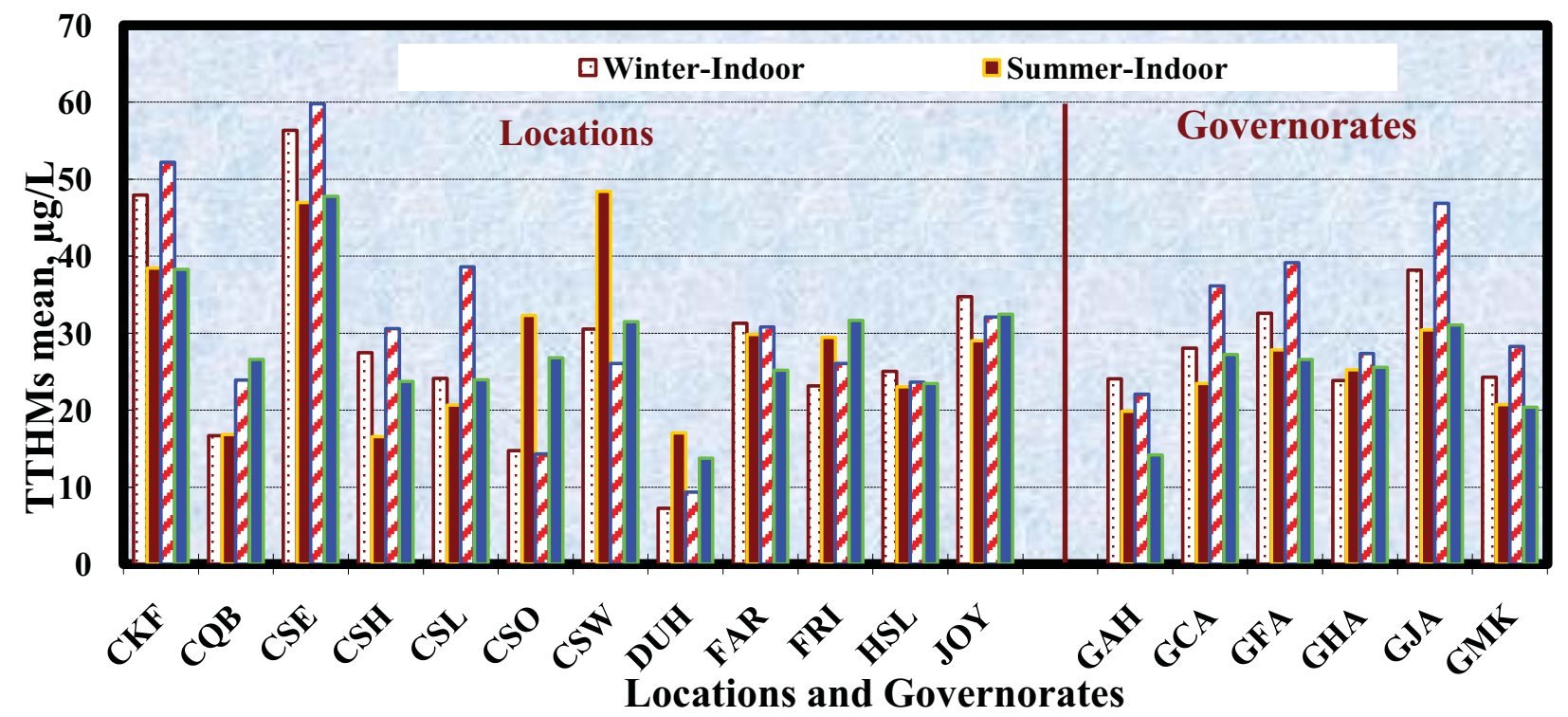

Fig. (8). Seasonal variation of TTHMs in the drinking water of various locations and Governorates (Winter: December - March; Summer: April - November). 
a number of different factors. First, the type of raw water source is different. It is seawater in this study while it is fresh water in other studies. Second, the average temperature of chlorinated water is low during the winter. Under such conditions, the evaporation rate of chlorine decreases, and its residual value in the distribution system as well as in the storage facilities at the buildings increases. Third, in addition to residual chlorine, THM formation depends on the amount of organic material present, which is higher in seawater and increases in winter due to its lower evaporation. The result is higher THM production which explains the prevailing pattern found in this study.

\section{CONCLUSIONS}

Chemical analysis for trihalomethanes was performed on 624 water samples collected from private residences (houses and apartments) and governmental buildings at 99 locations in 69 neighborhoods of the 6 Governorates of the State of Kuwait from December 2003 to May 2005. The analysis of the data from this comprehensive sampling program involving two points at each building (indoor tap and outdoor connection) led to the following conclusions:

There is strong variation in TTHM levels either between various sampling locations (buildings) or between $\boldsymbol{I}$ and $\boldsymbol{O}$ points of the same location.

(2) The highest values of TTHMs 91.0 and $90.5 \mu \mathrm{g} / \mathrm{L}$ for $\boldsymbol{I}$ and $\boldsymbol{O}$ samples, respectively, were recorded in CSE location, which are above the MCL recommended by the US EPA $(80.0 \mu \mathrm{g} / \mathrm{L})$, in addition to the highest means of 50.7 and $52.2 \mu \mathrm{g} / \mathrm{L}$ for $\boldsymbol{I}$ and $\boldsymbol{O}$ samples, respectively. On the other hand, DUH location shows the lowest values $(5.2$ and $5.0 \mu \mathrm{g} / \mathrm{L}$ for $\boldsymbol{I}$ and $\boldsymbol{O}$ samples, respectively), as well as the lowest means between all locations (14.2 and $12.1 \mu \mathrm{g} / \mathrm{L}$ for $\boldsymbol{I}$ and $\boldsymbol{O}$ samples, respectively).

(3) In agreement with previous findings, the TTHMs mean values are found higher for $\boldsymbol{O}$ samples than that of $\boldsymbol{I}$ samples.

(4) Strong correlations between residual chlorine and TTHM concentrations were seen.

(5) TTHM concentrations vary from one plant to another.

(6) During the last 17 years, the maximum recorded value of TTHMs in the indoor drinking water increased from $50.5 \mu \mathrm{g} / \mathrm{L}$ in 1988 (average $25.6 \pm 9.1$ $\mu \mathrm{g} / \mathrm{L}$ ) to a value of $90.5 \mu \mathrm{g} / \mathrm{L}$ in this study (average $45.5 \pm 2.6 \mu \mathrm{g} / \mathrm{L})$. This increase can be mainly attributed to the increase of organics in the Arabian Gulf seawater as a result of the Gulf crises and military operations occurring after 1990.

(7) In agreement with previous studies, we found that brominated THMs are the dominant species and BFM is the most dominant one. The minimum and maximum percentages were found to be 59.0 and $93.5 \%$ for BFM, 5.0 and $30.0 \%$ for CDBM, 0.5 and $9.7 \%$ for BDCM, and 0.0 and $2.9 \%$ for CFM, respectively. On the other hand, CFM and BFM were detected in $79 \%$ and $100 \%$ of samples with the highest values of 0.5 and $82.3 \mu \mathrm{g} / \mathrm{L}$, respectively. BDCM and DBCM were detected in $100 \%$ of samples with the highest values of 2.31 and $13.94 \mu \mathrm{g} / \mathrm{L}$, respectively.

(8) Seasonal variations indicated that no specific season is found to have the highest TTHM levels. As the specific climatic changes in Kuwait and Gulf area support the consideration of winter and summer as the dominant seasons, we found that TTHM levels are generally higher in winter and not in the summer, as seen in previous studies on drinking water obtained from freshwater sources (lakes, rivers, underground).

\section{ACKNOWLEDGEMENT}

The authors acknowledge and express their thanks and appreciation to the Kuwait Foundation for the Advancement of Sciences (KFAS) for financial support of this study (grant \# 2001-1505-03), and the Public Authority for Applied Education and Training (PAAET) for partial financial support and guidance. Special thanks are extended to the Organic Lab Staff, University of Iowa Hygienic Laboratory (UHL), Iowa City, Iowa, USA for their kind assistance, guidance, and technical support.

\section{REFERENCES}

[1] Richardson SD, Simmons JE, Rice G. Disinfection byproducts: the next generation. Environ Sci Technol 2002; 36: 198A-205A.

[2] Cantor KP. Drinking water and cancer. Cancer Causes Control 1997; 8: 292-308.

[3] Villanueva CM, Cantor KP, Cordier S, Jaakkola JJ, King WD, Lynch CF, Porru S, Kogevinas M. Disinfection byproducts and bladder cancer. A pooled analysis. Epidemiology 2004; 15: 357367.

[4] Yang CY, Xiao ZP, Ho SC, Wu TN, Tsai SS. Association between trihalomethane concentrations in drinking water and adverse pregnancy outcome in Taiwan. Environ Res 2007; 104: 390-395.

[5] Nieuwenhuijsen MJ, Toledano MB, Eaton N, Fawell J, Elliott P. Chlorination disinfection byproducts in water and their association with adverse reproductive outcomes: a review. Occup Environ Med 2000; 57: 73-85.

[6] Graves CG, Matanuska GM, Tardiff RG. Weight of evidence for an association between adverse reproductive and developmental effects and exposure to disinfection by-products: a critical review. Regul Toxicol Pharmacol 2001; 34: 103-124.

[7] Bove F, Shim Y, Zeitz P. Drinking water contaminants and adverse pregnancy outcomes: a review. Environ Health Perspect 2002; 110 (Suppl 1): 61-74.

[8] Morris RD, Audet AM, Arogelillo IF, Chalmers TC, Mosteller F. Chlorination byproducts and cancer: a meta-analysis. Am J Public Health 1992; 82: 955-963.

[9] Villanueva CM, Kogevinas M, Grimalt JO. Drinking water chlorination and adverse health effects: a review of epidemiological studies. Med Clin 2001; 117: 27-35.

[10] Krishna G, Swarupa TS, Luc BJ, Prabha DS. Chlorination byproducts, their toxicodynamics and removal from drinking water. J Hazard Mater 2007; 140:1-6.

[11] El-Shahat MF, Abdel-Halim SH, Hassan GA. Evaluation of trihalomethanes in water treatment plants outputs in Cairo, Egypt during 1991 to 1993. Bull Environ Toxicol 1998; 60: 502-506.

[12] Rodriguez MJ, Sérodes JB. Spatial and temporal evolution of trihalomethanes in three water distribution systems. Water Res 2001; 35: 1572-1586.

[13] Singer PC, Obolensky A, Greiner A. DBPs in chlorinated North Carolina drinking water. J Am Water Works Assoc 1995; 87: 8392.

[14] Ali MY, Riley JP. The distribution of halomethanes in the coastal waters of Kuwait. Marine Poll Bull 1986; 17: 409-414.

[15] Ali MY, Riley JP. The production of brominated methanes in desalination plants in Kuwait. Water Res 1989; 23: 1099-1106. 
[16] Ali MY, Riley JP. Distribution of halomethanes in potable waters of Kuwait. Water Res 1990; 24: 533-538.

[17] Latif NA, Al-Awadi FM, Colenutt BA. Trihalomethanes (THMs) formation in Multi-stage flash (MSF) desalination plants. Desalination. 1989; 74: 205-226.

[18] Saeed T, Khordagui H, Al-Hashash H. Contribution of power/desalination plants to the levels of halogenated volatile liquid hydrocarbons in the coastal areas of Kuwait. Desalination 1999; 121: 49-63.

[19] Elshorbagy WE, Abu-Qdais H, Elsheamy MK. Simulation of THM species in water distribution systems. Water Res 2000; 34: 34313439.

[20] Shams El Din AM, Arain RA, Hammoud AA. A contribution to the problem of trihalomethane formation from the Arabian Gulf water. Desalination 1991; 85: 13-32.

[21] Elshorbagy W, Abdulkarim M. Chlorination byproducts in drinking water produced from desalination in United Arab Emirates. Environ Monit Assess 2006; 123: 313-331.

[22] Kutty MPC, Nomani AA, Thankachan TS. Trihalomethanes in chlorinated drinking water from seawater desalination plants in AlJubail, Al-khobar and Khafji plants: 1991: IDA World Conference on desalination and water reuse, Vol. II.

[23] Kampioti AA, Stephanou EG. The impact of bromide on the formation of neutral and acidic disinfection by-products (DBPs) in Mediterranean chlorinated drinking water. Water Res 2002; 36: 25962606.

[24] Wu WW, Benjamin MM, Korshin GV. Effects of thermal treatment on halogenated disinfection byproducts in drinking water. Water Res 2001; 35: 3545-3550.
[25] Sadiq R, Rodriguez MN. Disinfection byproducts (DBPs) in drinking water and predictive models for their occurrence: a review. Sci Total Environ 2004; 321: 21-46.

[26] US Environmental Protection Agency (USEPA). Methods and guidance for analysis of water. Office of Water, Washington DC 20460. June 1999; EPA 821-C-99-004.

[27] US Environmental Protection Agency (USEPA) 2004 Edition of the Drinking Water Standards and Health Advisories. Office of Water Washington DC. Winter 2004; EPA 822-R-04-005

[28] Al-Otaibi A, Abdel-Jawad M. Water security for Kuwait. Desalination 2007; 214: 299-305.

[29] Krasner SW, McGuire MJ, Jacaugelo JG. The occurrence of disinfection byproducts in US drinking water. J Am Water Works Assoc 1989; 81: 41-53.

[30] Arora A, LeChevallier MW, Dixon KL. DBP occurrence survey. J Am Water Works Assoc 1997; 89: 60-68.

[31] Toroz I, Uyak V. Seasonal variations of trihalomethanes (THMs) in water distribution networks of Istanbul City. Desalination 2005; 176: 127-141.

[32] Golfinopoulos SK, Nikolaou AD. Survey of disinfection byproducts in drinking water in Athens, Greece. Desalination 2005; 176: $13-24$.

[33] Garcia-Villanova RJ, Garcia C, Gomez JA, Garcia MP, Ardanuy R. Formation, evolution and modeling of trihalomethanes in the drinking water of a town: I. At the municipal treatment utilities. Water Res 1997; 31: 1299-1308.

[34] Williams DT, Lebel GL, Benoit FM. Disinfection by-products in Canadian drinking water. Chemosphere 1997; 34: 299-316.

(C) Al-Mudhaf and Abu-Shady; Licensee Bentham Open

This is an open access article distributed under the terms of the Creative Commons Attribution License (http://creativecommons.org/license/by/2.5/), which permits unrestrictive use, distribution, and reproduction in any medium, provided the original work is properly cited. 